\title{
EL INCORPORACIONISMO ENTRE LA ESPADA DEL REALISMO MORAL Y LA PARED DEL POSITIVISMO EXCLUYENTE*
}

\author{
Pablo Ariel Rapetti \\ Universidad de Girona
}

RESUMEN. De acuerdo con Juan Carlos BAYÓn, el positivismo jurídico incluyente es inconsistente, por cuanto sus presupuestos alegadamente convencionalistas serían incompatibles con las consecuencias de la incorporación de principios morales como criterios de validez jurídica que esta corriente teórica asume como posibles. Concretamente, el positivismo incluyente enfrentaría un dilema: si sostiene que el derecho remite al juez a la moral positiva para la identificación de contenidos normativos, colapsa con la versión excluyente; si en cambio sostiene que el derecho remite al razonamiento moral sustantivo, se ve obligado a abandonar sus presupuestos convencionalistas, en favor del realismo moral. En este trabajo analizaré esta crítica de BAYón, e intentaré proponer un argumento con el cual afrontar dicho cuestionamiento.

Palabras clave: Positivismo jurídico incluyente, convencionalismo, razonamiento moral, objetivismo moral, criterios de validez jurídica.

\section{Inclusivism: between the rock of moral realism and the hard place of exclusive positivism}

ABSTRACT. According to Juan Carlos BAYÓN, inclusive legal positivism is inconsistent, insofar as its allegedly conventionalist assumptions seem to be incompatible with the consequences of the incorporation of moral principles as criteria of legal validity that this theory acknowledges as possible. In particular, inclusive positivism would face a dilemma: if it holds that the law directs the judge to recourse to positive morality in order to identify the legal contents, it collapses into the exclusive version of positivism; if, on the other hand, it holds that the law appeals to substantive moral reasoning, it becomes obliged to withdraw its conventionalist assumptions, in favor of moral realism. In this paper I will analyze BAYÓN's critique and try to offer an argument to counter that objection.

Keywords: Inclusive legal positivism, conventionalism, moral reasoning, moral objectivity, criteria of legal validity.

* Fecha de recepción: 21 de abril de 2014. Fecha de aceptación: 16 de junio de 2014.

El grueso de este trabajo fue escrito hace ya algunos años en el marco de una investigación más amplia financiada por la Universidad Nacional del Sur (Argentina) y supervisada por Pablo E. NAVARRO. Además de a Pablo y a mi universidad, agradezco especialmente a Macario Alemany, Amalia AmAYA, Manuel AtIEnZA, Andrés BouZAT, Diego Dei Vecchi, Ricardo GuAstini, José Juan Moreso, Ángeles RóDenAS y a dos evaluadores anónimos, por sus valiosos comentarios respecto de versiones previas. Contacto: pablo.rapetti@udg.edu. 


\section{INTRODUCCIÓN. BAYÓN Y UN DILEMA}

I n su trabajo Derecho, convencionalismo y controversia ${ }^{1}$, Juan Carlos BAYÓN desarrolla una interesante exposición de las tesis que, dentro del marco del llamado positivismo jurídico incluyente, se han ido elaborando a fin de desarrollar la tesis más básica de que, de manera contingente, la existencia y el contenido del derecho pueden ser identificados recurriendo a la moral, en la medida en que convencionalmente se establezca dicho recurso.

De esta manera, según el positivismo jurídico incluyente, la regla de reconocimiento de un sistema jurídico podría contemplar al razonamiento moral como criterio para distinguir las normas de una comunidad que son jurídicas, de otros tipos de normas. Esta tesis es la que se denomina comúnmente «tesis social débil», por oposición a la «fuerte», según la cual la existencia y el contenido de toda disposición jurídica se determina necesariamente a través de la verificación de ciertos hechos sociales, sin tener que recurrir nunca a la deliberación moral ${ }^{2}$.

Partiendo de la base de que la tesis social (en cualquiera de sus formas) sólo puede ser suscrita desde una perspectiva ontológica sobre el derecho que sea de tipo convencionalista - por oposición a enfoques realistas o escépticos-BAYÓN hace algunas distinciones en torno a las posibilidades expositivas del positivismo jurídico incluyente o incorporacionismo ${ }^{3}$. Así, una regla de reconocimiento incorporacionista podría adoptar las siguientes formas:

1. Regla de reconocimiento entendida globalmente como apelación a la corrección moral (Regla de reconocimiento simple).

Esta forma es la más simple y menos plausible: un sistema con una regla de reconocimiento que dice que se ha de hacer lo que es moralmente correcto. Una regla de este tipo en verdad no agregaría nada a la situación prejurídica referida por HART, para salir de la cual es justamente introducida la regla de reconocimiento ${ }^{4}$. El sistema jurídico en este caso sería — dice BAYÓN ${ }^{5}$ - «un sistema estático, no dinámico, y carecería en realidad de los rasgos mínimos que nos permitirían hablar de un sistema jurídico en sentido estricto».

2. Regla de reconocimiento que combina criterios de pertenencia al sistema: el del contenido y el de la fuente (Regla compleja). En este punto, se abren variantes:

2.a. Corrección moral como condición suficiente de validez.

1 BAYÓN, 2002: 57 y ss.

2 En palabras de Joseph RAZ, el más importante defensor de la versión excluyente del positivismo jurídico: «La diferencia entre la tesis social débil y la fuerte es que ésta insiste, mientras que la primera no, en que la existencia y contenido de toda disposición jurídica es totalmente determinada por fuentes sociales [...] La tesis débil, aunque verdadera, es insuficiente para caracterizar el positivismo jurídico [...] Denominaré a la tesis social fuerte: "la tesis de las fuentes" [...] Una disposición jurídica tiene una fuente si su contenido y existencia puede ser determinado sin usar argumentos morales...» RAZ, 1985: 66-67.

3 En ocasiones se distingue entre incorporacionismo y positivismo jurídico incluyente (o inclusivo). Vid., e.g., KRAMER, 2002: 2 y ss., que usa como criterio de distinción lo que aquí se verá infra, punto 2 de esta misma sección. No obstante, yo utilizaré estos términos como sinónimos, para evitar repeticiones narrativamente inconvenientes.

4 Hart, 1963: 113 y ss. (esp. 117).

5 BAYÓN, 2002: 71. 
Se trataría de que una norma — en la medida en que no contradiga a otra que pertenece al derecho en función de su fuente- sea también considerada perteneciente en virtud de su corrección moral. En este sentido, la regla de reconocimiento establece que la corrección moral es condición suficiente de validez jurídica ${ }^{6}$, pero subsidiariamente. Puede notarse que el caso anterior de una regla de reconocimiento simple que establece que es derecho lo moralmente correcto, es en verdad el supuesto por antonomasia de una que ponga a la moral como condición suficiente de validez, porque se trataría de una forma no subsidiaria.

2.b. Corrección moral como condición necesaria de validez.

Éste es el supuesto en que se predica la validez de una norma no sólo en razón de la fuente de la que emane, sino también de su conformidad de contenido con el de principios morales.

En este caso, vuelve a darse una bifurcación de alternativas:

2.b i) La corrección moral es en todos los casos condición necesaria de validez, pero en algunos es asimismo condición suficiente. Aquí sucede —según BAYÓNque se atiende a la correspondencia con el contenido de todos los principios morales correctos, con lo cual todos esos principios son derecho, en el sentido de que todos son parte de un criterio de identificación del derecho propio de la regla de reconocimiento.

2.b ii) La corrección moral es condición necesaria de validez pero nunca es condición suficiente. Aquí se atiende a la correspondencia de contenido con ciertos principios, determinados a su vez como parte de los criterios de identificación por otro criterio de identificación que atiende a las fuentes. Es decir, el contenido debe ajustarse al propio de principios que son parte del derecho por causa de su fuente ${ }^{7}$.

En este punto BAYÓN plantea un dilema en el que incurriría el incorporacionismo. Su primer cuerno es que si acepta que ciertas normas son jurídicas sólo en virtud de su corrección moral (de acuerdo a la moral crítica, objetiva), debe abandonarse la pretensión convencionalista; el segundo, que si sostiene que la identificación del derecho depende siempre de (la verificación de ciertas) convenciones sociales, exclusivamente, entonces colapsa con el positivismo jurídico excluyente. El incorporacionismo necesitaría de una convención compleja de recurrir a criterios no convencionales (convención de recurrir al razonamiento moral sustantivo) y la suscripción de algún tipo de objetivismo moral tal que no se haga la remisión a lo que la comunidad crea correcto, sino a lo que verdaderamente lo sea (de ahí que se trate de razonamiento moral sustantivo) ${ }^{8}$. Sin embargo, una presunta convención de seguir criterios no convencionales es para BAYÓN una convención sólo aparente, con lo cual el resultado de esta opción sería que deberían abandonarse las premisas convencionalistas. En definitiva, el positivismo

6 BAYÓN no hace uso de la distinción que hace COLEMAN entre «funciones de validación y de identificación de la regla de reconocimiento» y aun de «regla de reconocimiento como regla de validación» como distinta a una «regla de identificación». Por lo mismo, tampoco haré uso de estas distinciones aquí, aunque creo que constituyen un tema de sumo interés para el debate general en torno al positivismo jurídico incluyente y sus variantes. Al respecto, vid., por caso, COLEMAN, 1998: 287-319.

7 El caso más común sería el de la mención de los principios en un texto constitucional. BAYÓN, 2002: 72.

8 La remisión a lo que la comunidad crea correcto sería inviable porque en definitiva conformaría un criterio social de identificación que conduciría a las tesis excluyentes. 
jurídico incluyente resultaría insostenible dentro del marco del convencionalismo, so pena de disolverse en el positivismo excluyente?

En el presente trabajo trataré de analizar en qué medida se encuentra el positivismo jurídico incluyente comprometido por este dilema e intentaré argumentar en favor de una posible resolución. Para ello, en la sección 2 me referiré brevemente a dos diversas formas de distinguir al convencionalismo en subtipos. Estas distinciones (la segunda de las cuales es ofrecida por el propio BAYÓN) servirán para mostrar que el riesgo de abandono del convencionalismo es dependiente del subtipo de éste que se asocie al positivismo jurídico incluyente. En la sección 3 expondré los lineamientos básicos de la teoría metaética de Carlos NiNO, pues representa un tipo de teoría tal vez capaz de ser ligada al incorporacionismo de manera que éste no caiga en alguno de los cuernos del dilema de Bayón, quien — sugeriré también- propone asimismo una alternativa que es sustancialmente análoga a la de la asociación a esta teoría (con lo cual estaría también proponiendo una salida para el incorporacionismo del dilema en que primeramente lo colocó). En la sección 4 insinúo un argumento distinto, paralelo (pero no incompatible con el primero) para enfrentar el dilema en cuestión.

En la sección 5 discuto un argumento puntual en contra de la idea de que alguna forma de objetivismo moral es un verdadero compromiso conceptual para el positivismo jurídico incluyente, para así dar los primeros pasos hacia la tesis más general de que en efecto lo es. El punto es sólo un bosquejo, puesto que un desarrollo detallado excedería el marco de este trabajo, pero básicamente quiere decir que, de ser falso el objetivismo moral, el incorporacionismo pierde sustento teórico y resulta fagocitado por el positivismo jurídico excluyente.

\section{LAS EXIGENCIAS SOBRE EL CONVENCIONALISMO}

Creo que el planteamiento de este dilema entre el abandono de los presupuestos convencionalistas en favor del realismo moral o el colapso con la versión excluyente del positivismo jurídico es muestra de que BAYÓN quizá sea demasiado exigente en punto a lo que se requiere para hablar con sentido de «convencionalismo».

Siguiendo a Claudina ORUNESU ${ }^{10}$, quien toma la distinción de Ronald DwORKIN ${ }^{11}$, puede distinguirse entre consensos «por convención» y «por convicción». En los primeros, se sigue una determinada pauta porque todos la han adoptado y esa aceptación general es la que lleva a hacer lo que la pauta dispone. En los segundos, en cambio, existe en un grupo social una práctica concurrente, pero los individuos adhieren a la regla por sus convicciones personales (cuando comparten los mismos principios morales, por ejemplo), y no porque los demás la sigan ${ }^{12}$.

De esta manera, es dable decir que una regla puede ser convencional no necesariamente porque haya un acuerdo general sobre ella, sino simplemente porque, por las

\footnotetext{
9 BAYÓn, 2002: 75.

10 Orunesu, 2007: 36-37.

11 Dworkin, 1978: 111; 1986: 135-136.

12 Orunesu, 2007: 37.
} 
razones que fueren, está conformada la práctica concurrente de seguirla, aunque no se haya dado a su respecto una convención en sentido fuerte (no media un acuerdo), esto es, aunque cada individuo no la siga porque el resto de la comunidad también lo hace, sino solamente por razones personales varias. Se trataría de una convención en sentido débil ${ }^{13}$.

Esto representa, por ende, una forma distinta, menos cargada conceptualmente, de entender el convencionalismo. Así, una regla de reconocimiento incorporacionista, que establezca conjuntamente criterios de validez relacionados con la fuente y con la corrección moral, puede remitir, de la mano de este segundo criterio, a la moral objetiva, no porque ésta exista en virtud de acuerdos, sino meramente en el sentido de que hay una práctica concurrente (una convención débil) que la conforma.

No obstante, es importante tener presente que aquí pueden presentarse dos problemas de caracterización: el de la convencionalidad de la moral y el de la convencionalidad de la regla de reconocimiento. El compromiso con la idea de la regla de reconocimiento como una instancia de consenso por convicción podría traer ulteriores inconvenientes; sin embargo, veremos que el núcleo de la crítica de BAYÓN reside más bien en su caracterización del razonamiento moral ${ }^{14}$. Es más, puede decirse que en su artículo BAYÓN presupone el carácter convencional de la regla de reconocimiento, y en este sentido asumiré lo mismo en el presente trabajo.

Hay entonces un primer elemento por el cual tendría sentido hablar de una «convención que reenvía a un criterio no convencional»: matizando la no-convencionalidad del punto de llegada. Y en función de ello es posible considerar que cuando un juez a la hora de aplicar el derecho deba recurrir a la moral, en verdad tiene que desarrollar un razonamiento moral genuino. La moral no está plenamente determinada por los acuerdos de la comunidad, es decir, no es convencional en el sentido fuerte, pero cabe la posibilidad de que opere en la línea de las convenciones en sentido débil. No entraré todavía en más detalle de esta consideración, pero aquí cabe decir que ésta no parece lo suficientemente implausible prima facie como para que sea rechazada de antemano, sin adentrarse con cierta profundidad en un argumento específico al respecto ${ }^{15}$.

Y es que, como dice RóDENAS siguiendo a MORESO, el juez, el intérprete, debe cumplir su rol actuando sobre un trasfondo moral y «el trasfondo moral que opera sobre el intérprete no es un discurso que se libre al margen de nuestras convenciones;

13 Ibid., 37. Esta caracterización será detallada y cualificada infra, sección 3 in fine.

14 Entonces, también debe tenerse presente que la regla de reconocimiento es un conjunto de criterios a donde recurrir en busca de respuestas jurídicas, pero difícilmente puede vérsela como la regla que directamente proporciona dichas respuestas. Tal vez éste sea un punto implícitamente asumido por momentos en la crítica de Bruno CELANO a la consideración de la regla de reconocimiento como una convención, en el sentido de que, si lo fuera, ello igualmente sería banal, poco interesante e informativo (CELANO, 2009: 61 y ss.). Creo que lo apuntado aquí puede servir como inicio de respuesta a este tipo de objeción, sumado tal vez a consideraciones metodológicas más generales sobre el interés de las investigaciones filosóficas y la manera en la que éstas arrojan frutos (si como tesis-producto, como pareciera asumir el tipo de crítica que formula CELANO, o como discusión-proceso, como me inclino a pensar). No puedo desarrollar más esta cuestión aquí, pero puede verse al respecto a VilajosAnA, 2010: 498-499. Más en general sobre el valor de las investigaciones filosóficas como proceso, más que como producto, puede verse también a GARCÍA-CARPINTERO, 2010: 21-22.

15 Por otro lado, parece que hay una cercanía notable entre las nociones de convención en sentido fuerte y la de contrato, y uno parece tener buenas razones para no asimilar el funcionamiento de la moralidad muy simplemente al de la negociación contractual. 
por el contrario, es un discurso condicionado por nuestras convenciones» ${ }^{16}$. Al menos esto es así con aquellas «concepciones que asumen que (bajo ciertas condiciones) las prácticas sociales existentes están dotadas de un cierto valor moral que debe ser tomado en consideración en el razonamiento jurídico justificativo» ${ }^{17}$ como puede ser, por ejemplo, el constructivismo ético desarrollado por Carlos $\mathrm{NINO}^{18}$, sobre el que volveré más adelante ${ }^{19}$.

Y más tarde diré también alguna otra cosa sobre el contexto de la exposición que MORESO hace de esta idea ${ }^{20}$; ahora, sin embargo, proseguiré con el argumento de BAYÓN según el cual si no hay acuerdo respecto de lo que la moral objetiva exige, aun cuando lo haya respecto de que la validez jurídica dependa en parte de la conformidad con la moral objetiva, no hay en propiedad convención alguna. Se trataría de una convención vacía, que se autoanula.

BAYÓN no sólo parece manejar una versión estricta de convencionalismo, sino también sobre qué tener por «genuino» razonamiento moral. Él mismo establece una distinción entre tipos de convencionalismo: así, se refiere a uno superficial y uno profundo. De acuerdo con el primero, existe una regla compartida cuando existe en la comunidad un acuerdo explícito sobre el conjunto de aplicaciones correctas de ella. Pero este tipo de convencionalismo vuelve un sinsentido la idea de un error generalizado sobre las exigencias de una regla social: si lo hubiera no estaría verdaderamente conformada una regla tal. Sucede genéricamente que —en palabras de BAYÓN- «el convencionalismo superficial simplifica en exceso la naturaleza y condiciones de existencia de los hechos convencionales.» ${ }^{21}$

De aquí la plausibilidad del convencionalismo que llama profundo, según el cual «la existencia de criterios públicos se muestra o exhibe en el acuerdo en torno a ciertos casos paradigmáticos que se reconocen como aplicaciones correctas de la regla, sin que ello quiera decir que la extensión de dichos criterios se contraiga a esas aplicaciones» ${ }^{22}$.

Lo que define al convencionalismo profundo no es el acuerdo en torno a las aplicaciones concretas de la regla, sino el trasfondo de criterios compartidos. Por supuesto, aun para esta concepción podrán presentarse casos de genuinos desacuer$\operatorname{dos}^{23}$, lo que abona una vez más la adhesión al convencionalismo sobre el derecho en el sentido de que los límites de este último están dados por los límites de nuestras convenciones ${ }^{24}$.

16 RÓDENAS, 2003: 441.

17 Ibid., 442.

18 Vid. NinO, 1989a: cap. 3 y 1992: 66-77. En este último libro, el autor se refiere específicamente a un modelo de racionalidad para nuestras prácticas constitucionales. En el primero, desarrolla una teoría metaética, que también expone en NiNO, 1989b.

19 Infra, sección 3.

20 Infra, sección 5.

21 BAYÓN, 2002: 79.

22 Id.

23 Ibid., 80.

24 Id. y RÓDENAS, 2003: 443. Nótese el cambio en la propia terminología que utiliza BAYÓN, que pasa de hablar de «acuerdos» a «criterios compartidos», lo cual podría mostrar que en su trabajo también subyace una forma de la distinción entre consensos por convención y por convicción. Ello, por supuesto, no quiere decir que la categoría de consensos por convención sea coextensiva con la de convencionalismo superficial, ni que la de consensos por convicción lo sea con la de convencionalismo profundo. 
Luego de caracterizar al convencionalismo profundo, es el propio BAYÓN quien delinea un esquema de estrategia epistemológica con la cual acceder a ese trasfondo de criterios compartidos que le son definitorios. Ese esquema, en sus palabras ${ }^{25}$ :

ha de tomar la forma de un razonamiento de naturaleza holista que, partiendo de lo que a primera vista parecen ser casos paradigmáticos, intente establecer qué es lo relevante en ellos; formule hipótesis acerca de los criterios de aplicación que parece poner de manifiesto la consideración de esos factores como relevantes; y vuelva después a considerar otros casos - reales o hipotéticos- que nos parezcan igualmente claros a fin de poner a prueba la admisibilidad de dichas hipótesis acerca de los contornos de nuestros criterios. [...] En suma, este ir y venir — que recuerda obviamente a la idea rawlsiana de un equilibrio reflexivo— no es sino una deliberación en busca de coherencia entre lo que nosotros estamos dispuestos a considerar casos incuestionablemente claros —incluso tras esta clase de filtro- y las mejores hipótesis que podamos elaborar para articular y explicitar los criterios compartidos a la luz de los cuales precisamente los consideramos claros.

Reténgase especialmente este esquema porque en lo sucesivo volveré con énfasis sobre él ${ }^{26}$. Por el momento, no obstante, obsérvese que es capital el hecho de que BAYÓN mismo pone de relieve que el convencionalismo es entendible en distintas formas y que al menos una de ellas permite hablar de convenciones interpretativas no vacías. De esta manera, el autor pretende que es posible enfrentarse a lo que llama el «argumento del contraste con la práctica», que algunos han opuesto al positivismo jurídico, y según el cual la práctica jurídica actual desmentiría la tesis de las fuentes sociales, porque constantemente se estaría recurriendo a razonamientos y deliberaciones complejas que escapan a la mera constatación de acuerdos sociales. La cuestión ahora pasa por resaltar que las exigencias conceptuales que inicialmente establece para caracterizar al convencionalismo que liga al positivismo jurídico, parecen ser luego de algún modo relajadas.

No obstante, a pesar de reconocer la forma de convencionalismo que él llama profundo, a partir de la cual delinea su propia estrategia epistemológica, BAYÓN concluye su trabajo diciendo que ${ }^{27}$

por complejo y controvertido que pueda ser el razonamiento encaminado a establecer el contenido de nuestras convenciones en una práctica deliberativa, no ha de ser confundido con el genuino razonamiento moral, cuyo desarrollo no está condicionado por constricciones determinadas convencionalmente.

Como adelanté más arriba, parece entonces que lo que ahora se recarga de exigencias conceptuales es el razonamiento moral, de modo que sólo resultará «genuino» cuando no esté restringido por convenciones sociales. Creo que esta afirmación necesitaría alguna argumentación adicional. Por lo pronto, parece chocar con opiniones como la ya citada de RÓDENAS: «El trasfondo moral que opera sobre el intérprete no es un discurso que se libre al margen de nuestras convenciones; por el contrario, es un discurso condicionado por nuestras convenciones» ${ }^{28}$. Pero más allá de esto, BAYÓN parecería necesitar definir con precisión qué entiende por «genuino razonamiento moral», y más en general por «razonamiento moral».

\footnotetext{
25 BAYÓN, 2002: 80-81.

26 Infra, secciones 3 y 5 .

27 BAYÓN, 2002: 81.

28 RÓDENAS, 2003: 441.
} 


\section{LAS EXIGENCIAS SOBRE EL RAZONAMIENTO MORAL. EL EJEMPLO DE UNA TEORÍA METAÉTICA}

Para observar con más profundidad la cuestión de si el genuino razonamiento moral puede estar o no condicionado por nuestras convenciones sociales, veremos ahora unos breves puntos del desarrollo de la concepción metaética constructivista de Carlos NinO. En su libro Ética y derechos bumanos, escribe ${ }^{29}$ :

La moral social o positiva es el producto de la formulación y aceptación de juicios con los que se pretende dar cuenta de principios de una moral ideal. Sin la aspiración de actuar y juzgar de acuerdo con una moral ideal no habría moral positiva. Las reglas de la moral positiva se generan a partir de un tipo de discurso en el que se formulan juicios que pretenden referirse no a tales reglas de la moral vigente sino a los principios de una moral ideal. [...] De modo que es equivocado aislar completamente la moral ideal de la moral social.

Y sigue más adelante ${ }^{30}$ :

En la identificación de la moral que está vigente en diversas sociedades, por un lado, y de un sistema moral ideal, por el otro, tal vez haya que hacer ajustes recíprocos. Por ejemplo, no tendría sentido concebir como moral una concepción ideal tal que, independientemente de la validez de sus enunciados, no tuviera propiedades en común con concepciones vigentes en distintos tiempos y sociedades.

De aquí ya puede apreciarse que la propuesta de NiNO es claramente una que intenta conciliar convencionalismo y objetivismo ${ }^{31}$. La suya es una perspectiva que ve a la moral como una práctica discursiva dirigida a obtener una convergencia en acciones y actitudes, a través de una aceptación libre, por parte de los individuos, de principios para guiar sus acciones y sus actitudes frente a acciones de otros ${ }^{32}$.

Como es sabido, esta teoría es en gran medida tributaria de la desarrollada por John RAWLS, quien sostiene ${ }^{33}$ :

La visión constructivista acepta desde el comienzo que una concepción moral no puede establecer sino un marco laxo para la deliberación, la cual tiene que confiar de forma muy considerable en nuestras facultades de reflexión y juicio. Estas facultades no están fijadas de una vez por todas, sino que son desarrolladas por una cultura pública compartida y por ende modeladas por esa cultura.

Para NinO, la justificación de conclusiones morales puede realizarse a través de un proceso de equilibrio reflexivo. Ésta es la famosa idea de RAWLS según la cual ha de desarrollarse una armonización retroalimentadora entre convicciones morales particulares y principios generales que den cuenta de ellas, a la que el filósofo argentino añade un tercer elemento, cual es el de las reglas o aspectos formales del discurso moral que permiten derivar tales principios ${ }^{34}$. Es mediante este proceso de armonización no sólo

29 NiNO, 1989a: 93 (resaltado en el original).

30 Ibid., 95.

31 RÓDENAS, 2003: 442.

32 En palabras de NINO: «Cuando describimos la moral de cierta sociedad debemos dar cuenta no sólo de las reglas que allí rigen y las virtudes de carácter que exhiben los individuos sino también del discurso que ellos desarrollan para favorecer y oponerse a ciertas conductas o prácticas. Este discurso es una práctica social y como tal es históricamente contingente». NinO, 1989a: 103 (resaltado en el original).

33 RAWLS, 1999: 251.

34 Para profundizar en lo relativo a su versión del equilibrio reflexivo, vid. NiNO, 1989a: 105 y ss. 
con lo que se obtendrían justificaciones morales, sino también, correlativamente, con lo que se producen los ajustes recíprocos entre moral positiva y moral ideal mencionados supra. Estos ajustes y, en general, todo el proceso por el que se llega a ellos, son, creo, una muestra clara de un esquema para el razonamiento moral genuino ${ }^{35}$ que está condicionado por convenciones sociales (a la vez que puede redundar en el condicionamiento — «ajuste»— de ellas ${ }^{36}$ ).

Es importante señalar que para NiNO la justificación y validez de los principios morales está dada por la satisfacción de los presupuestos de la discusión moral. Aunque no es necesario el logro de consensos efectivos en discusiones reales sobre pautas morales concretas, un punto relevante es que evidentemente esos presupuestos representan que en el propio plano ontológico, es decir, el de la constitución de esos principios y pautas, hay una nota de interacción social necesaria. El que se dependa de presupuestos de la discusión moral implica al menos una disposición actualizable de puesta en común y contrastación de juicios morales personales. La práctica discursiva moral es colectiva, y lo son sus presupuestos, y allí ya hay una nota de constreñimiento social al razonamiento sustantivo, aun cuando la conexión entre dichos presupuestos y los principios morales sustantivos no esté dada necesariamente por un proceso colectivo (y, de allí, como se dijo, que no se requieran consensos concretos) ${ }^{37}$. Con ello, parece ya haber elementos para evadir el realismo ontológico fuerte que preocupa a BAYÓN.

Hay que remarcar asimismo que en el plano epistemológico la presencia de lo colectivo, a modo de restricciones y constreñimientos al razonamiento individual, es en la teoría de NiNO todavía más notoria. Se trata no ya de la constitución de la validez de los principios y pautas morales, sino de la forma de obtener conocimiento de dichos principios moralmente válidos. En este sentido, (como con el plano ontológico) busca una vía intermedia entre individualismo y societarismo, que reúna elementos de ambos y no los trate como opciones enteramente excluyentes. El esquema del equilibrio reflexivo es precisamente la estrategia epistemológica propuesta para el razonamiento moral ${ }^{38}$.

Esta estrategia intenta hacerse cargo de una situación de hecho muy evidente: la de la tensión constante que hay en la vida diaria de todas las personas, a la hora de decidir cursos de acción, entre juicios de valor basados en intuiciones personales muy profundas (y/o en argumentos más o menos desarrollados), y entre juicios de valor cuyo primer fundamento reside en el apoyo en la práctica generalizada, opinión común o más difundida, etc. El equilibrio reflexivo es, en última instancia, equilibrio entre estos dos elementos.

Los consensos (obtenidos bajo ciertas condiciones) cumplen en este plano un papel muy importante, pues son instrumentos epistémicos de valor especial, indicadores fiables. En palabras de $\mathrm{NINO}^{39}$

el consenso efectivo es una forma privilegiada de conocimiento moral, ya que cuando hay consenso unánime sobre cierta solución moral, después de un proceso de discusión, hay una altísima probabilidad de que la solución sea efectivamente correcta.

\footnotetext{
35 El proceso como razonamiento en sí, y los ajustes como el producto de éste.

36 NiNO, 1989a: 44.

37 Vid. NiNO, 1994: 164-173.

38 NiNO, 1989b: 93 y ss.

39 NINO, 1989b: 176 (resaltado en el original).
} 
Llevado todo esto al plano de la decisión judicial, puede decirse que un juez, al verse obligado a evaluar la corrección moral como criterio de validez jurídica, debe «introducirse» en una especie de equilibrio reflexivo, llevar adelante, desarrollar, el procedimiento. Este rol es activo, no se queda en la mera constatación de convenciones sociales, sino que demanda la argumentación sustantiva, el contrapunto a esas convenciones con argumentos e intuiciones personales elaboradas. En esta medida, el razonamiento que realiza parece tener buenas cartas para ser considerado un razonamiento sustantivo genuino. Por ello, el incorporacionismo al admitir esto para la identificación del derecho se diferenciaría del positivismo jurídico excluyente.

Tomando esta concepción, bastaría cierto grado de acuerdo sobre exigencias de la moral (casos paradigmáticos) para mostrar que hay un trasfondo de criterios compartidos y que la remisión a la moral no implica salirse del convencionalismo, que no se incurre en convenciones que se autoanulan. Por otro lado, según dice COLEMAN en lo que hace al tratamiento judicial de casos, es claro que los jueces no podrían estar en desacuerdo en todos esos casos o la mayoría de ellos, porque allí se haría ininteligible la idea de que están siguiendo la misma regla ${ }^{40}$. Así puede entenderse que todos podamos estar equivocados sobre algunas (o muchas) creencias morales, pero que no podríamos estarlo sobre todas o la gran mayoría de ellas ${ }^{41}$. Por lo demás, el equilibrio reflexivo es también el procedimiento con el cual podrían subsanarse equivocaciones tales, excluyendo, en última instancia, creencias, que no obstante son importantes al menos en un principio, porque constituyen parte del objeto sobre el que se realiza dicho procedimiento de deliberación.

Finalmente, debe resaltarse que en definitiva, la propuesta epistemológica de NiNO para arribar a justificaciones morales no difiere en nada relevante de la que BAYÓN esboza para el convencionalismo profundo que propone. Siendo así, parece haber una fuerte razón más para preguntarse cómo justifica este último su afirmación de que el desarrollo del genuino razonamiento moral no está condicionado por constricciones determinadas convencionalmente. Por otro lado, con ello puede verse que BAYÓN mismo da al positivismo incluyente una vía de salida de la encrucijada en que primeramente lo había colocado. Frente a la cuestión de si con esta forma «profunda» de convencionalismo nos encontramos ante supuestos de genuina deliberación moral, cabe sostener que al menos si se adopta una teoría metaética constructivista como la de NINO, es posible afirmar que sí.

Resta simplemente hacer un comentario sobre la conexión entre los dos elementos de respuesta ofrecidos hasta aquí: la noción de convención débil, por un lado, y la opción por la metaética constructivista de tipo rawlsiano, por el otro.

$\mathrm{Al}$ respecto puede decirse lo siguiente ${ }^{42}$. Uno de los problemas que podría aquejar a la noción de consenso «por convicción» es el de la forma en que distinguirla de la mera convergencia de acciones y actitudes. Dicho de otro modo: parece necesario dotar de sentido consensual a la noción, para que su nombre no quede en un simple truco verbal. Pues bien, creo que aquí es donde puede entablarse la conexión entre esta no-

\footnotetext{
40 Coleman, 2001: 116.

41 Vid. especialmente RAWLS, 1999: 256-257.

42 Agradezco a Maribel NarváEz Mora por haber discutido conmigo sobre este punto.
} 
ción y la metaética constructivista: el equilibrio reflexivo entre intuiciones morales muy arraigadas y juicios morales argumentados («esclarecidos»), por un lado, y pautas morales socialmente compartidas, positivizadas, por el otro, dota de sentido a la noción de convención débil en tanto que vía intermedia entre el extremo de la mera convergencia irreflexiva de acciones y actitudes, donde las consideraciones de moralidad positiva no cumplen ningún papel, y el otro extremo, en el cual el acatamiento de una regla por parte de otros es razón suficiente para el acatamiento de la misma regla por parte de uno.

Puesto en términos de condiciones: mientras que la noción de convención fuerte hace del acatamiento ajeno una condición suficiente para el acatamiento propio, y que en el caso de la mera convergencia no opera ninguna razón en tanto condición (la convergencia es un mero hecho fortuito); para la noción de convención débil, en las pautas de moralidad social hay al menos condiciones contribuyentes (al modo constraints) para las razones sobre la base de las cuales adoptar cursos de acción ${ }^{43}$.

\section{UNA VARIANTE: ¿CONVENCIONALISMO «TODO-O-NADA»?}

A lo largo de este texto he asumido implícitamente, con BAYÓN ${ }^{44}$, que el convencionalismo en los ámbitos del derecho y la moral impone rechazar el realismo metafísico, pero que ello no implica que dicho realismo deba también ser rechazado en relación con otra clase de entidades. No desarrollaré demasiado la siguiente idea —que no es central a mi intención primaria de respuesta a BAYÓN en este trabajo- pero es posible preguntarse si el convencionalismo (en cualquiera de sus formas, pero, sobre todo, el profundo) requiere que todas las normas que se identifiquen como parte de un sistema jurídico, lo sean en virtud de convenciones que les den origen.

Intentaré trazar una analogía. ALCHOURRÓN y BULYGIN definen a un sistema normativo como un conjunto de enunciados en cuyas consecuencias hay alguna normati$\mathrm{va}^{45}$. Luego, identificando con KELSEN, HART y RAZ a la sanción como característica distintiva del derecho (del orden jurídico), definen a un sistema jurídico como un tipo de sistema normativo que contiene enunciados prescriptivos de sanciones, es decir, entre cuyas consecuencias hay normas o soluciones cuyo contenido es un acto coactivo ${ }^{46}$.

43 En el texto suyo que he venido citando, Claudina ORUNESU sostiene que en los consensos por convicción, o convenciones en sentido débil, la convergencia es accidental (ORUNESU, 2007: 37). Creo que esto es un error, en particular en el contexto de una discusión también dirigida específicamente al dilema planteado por BAYÓN al incorporacionismo, que pretende hacer uso de la noción de convención débil por su capacidad de dar cuenta de un mayor número de situaciones que la más restrictiva versión fuerte. La convergencia no puede ser un mero accidente, es de hecho condición necesaria de la existencia de cualquier consenso. En este sentido, creo que la asociación que aquí propongo entre la noción de convención débil y la metaética constructivista permite enfatizar mejor el carácter convencional de los consensos por convicción (aunque éste sea comparativamente menor al de las convenciones fuertes). En ARENA, 2012, pueden encontrarse distinciones mucho más finas que las aquí trazadas respecto de formas de convencionalismo, y consideraciones alternativas sobre la relación entre convergencia y convención. No creo que nada de lo que de tan sustancioso análisis surge se oponga al punto que aquí quiero defender (sino todo lo contrario), pero sí pienso que es innecesario para mis propósitos actuales recurrir a un aparataje filosófico de tanta sofisticación.

44 BAYÓN, 2002: 82 (n. 10).

45 Alchourrón y Bulygin, 1975: 93. Según estos autores, hay una consecuencia normativa cuando se produce una correlación deductiva entre un caso y una solución.

46 Ibid., 106 
Como puede apreciarse, de acuerdo con este criterio un sistema de enunciados no requiere que todas sus consecuencias sean normativas para conformar un sistema normativo, de la misma manera en que un sistema normativo no tiene por qué estar conformado por enunciados que establezcan — todos- sanciones, para ser jurídico. Por consiguiente, es claro que el derecho de una comunidad se compone no sólo de normas, sino también de otros elementos. Por dar un ejemplo poco controvertible, incluye también definiciones o postulados de significación ${ }^{47}$.

En punto a la discusión abordada en este trabajo, podría sostenerse analógicamente que para mantener la ligazón del positivismo jurídico incluyente al convencionalismo no es necesario que sean de origen convencional todos los elementos, individualmente considerados, que, por la explicación del derecho que hace esta versión del positivismo, se identifiquen como jurídicos. Podría pretenderse que lo que hace que ontológicamente pueda decirse que se trata de un sistema jurídico convencionalista, es que las normas jurídicas que lo componen son fundamentalmente producto de convenciones ${ }^{48}$. No necesitamos decir que un sistema jurídico se compone de normas jurídicas exclusivamente; de la misma manera, quizás no sea necesario que todos los componentes del sistema emanen de convenciones para seguir abrazando la tesis convencionalista, porque ¿es el convencionalismo conceptualmente «de todo o nada»?

Por supuesto, en función de la teoría metaética que aquí he comentado, no hay moral en una realidad metafísica del todo ajena a nuestras convenciones sociales. A lo que voy es a que, aun si se adoptara un enfoque según el cual el realismo metafísico sobre la moral pudiera ser verdadero, no surgiría inmediatamente que el convencionalismo deba ser abandonado, sin una argumentación ulterior ${ }^{49}$.

47 Ibid., 97 y 107 y su texto «Definiciones y normas», en AlCHOURRÓN y BuLYGIN, 1991: 439 y ss.

48 Por supuesto, una propuesta completa en este sentido requeriría también del aporte de un criterio de medición y algún indicativo de qué y cuánto vale como composición fundamental de un sistema jurídico. Por así decirlo, se necesitaría de una tesis epistémica que acompañe a la tesis ontológica sugerida (apenas) en el texto. La elaboración de esto excedería en mucho los objetivos del presente trabajo.

49 Dicho esto, vid. NiNO, 1989a: 74-75, donde plantea el ejemplo imaginario de una piedra que tuviese la propiedad de tomar distintos colores en función del valor moral que tengan los hechos que sucedan cerca de ella. Reconocer que la piedra tiene dicha propiedad presupondría la correlación de ciertos juicios de valor con ciertos hechos. Haber formulado esos juicios es haber tomado partido previamente sobre el hecho a evaluar. De manera que «[u]na ética metafísica, de ser aceptada, no necesariamente tendrá éxito en fundamentar nuestros juicios de valor; y, a la inversa, tal fundamentación no conduce necesariamente a una ética metafísica» (p. 75). Por consiguiente, parecería que incluso si existiese una piedra como la imaginada por NiNO, habría buenas razones para dejar la fundamentación racional de juicios morales a algún tipo de práctica convencionalista. Un argumento similar es un leit motiv del excelente libro de BRENNAN, 1977. Además, en palabras de RAWLS: «[L]a objetividad o subjetividad del conocimiento moral no depende de la cuestión de si existen entidades ideales de valor, o de si los juicios morales son causados por emociones, o de si hay una diversidad de códigos morales por todo el mundo, sino simplemente de la siguiente cuestión: ¿existe un método razonable para validar o invalidar reglas morales dadas o propuestas así como las decisiones que se adoptan basándose en ellas?», RAWLS, 1999: 61. Pero vid. también que en otro de los artículos de ese libro dice: «A decir verdad, ni siquiera se excluye que la forma de dar cuenta de algunas nociones [morales] deba ser constructivista, mientras que la de otras no» (p. 252); aun cuando, como es sabido, para él «[f]uera del procedimiento de construir los principios de justicia, no hay hechos morales» (p. 213).

Al margen de lo anterior, no se me escapa lo curioso de utilizar a ALCHOURRÓn y BULYGIN como fuente para un argumento con el que intentar salvar de una objeción teórica puntual al positivismo incluyente, posición que expresamente han rechazado. Con algo de suerte, la estrategia hasta podría agregarle al (esbozo de) argumento cierto valor retórico. Por lo demás, vale la pena señalar que en un trabajo suyo BuLYGIN se refiere expresamente al artículo de BAYÓN y al dilema que presenta al incorporacionismo. A mi entender, la reconstrucción que allí hace de dicho dilema es errada, porque lo presenta como el dilema entre colapsar con el positivismo excluyente o bien asumir el objetivismo moral (BULYGIN, 2006: 109 y ss.). Esta segunda, 


\section{MORESO Y LA NECESIDAD DEL OBJETIVISMO MORAL}

Quisiera volver ahora sobre lo escrito por José Juan MORESO en torno a la necesidad del objetivismo moral para el positivismo jurídico inclusivo ${ }^{50}$.

El punto central en que pretendí hacer hincapié en este trabajo es que la deliberación moral no necesariamente debe estar al margen de nuestras convenciones sociales. Trayendo a colación la teoría metaética elaborada por NiNO, busqué mostrar cómo pueden haber (de hecho, hay) teorías morales que colocan a dicha deliberación justamente dentro de un marco condicionado por convenciones sociales, a la vez que condicionante de ellas.

En su trabajo En defensa del positivismo jurídico inclusivo ${ }^{51}$, MORESO dice que el positivismo incluyente no necesita adoptar ninguna clase de objetivismo moral para mantenerse consistente. Para ello, toma la distinción que suele hacerse entre conceptos morales ligeros y densos. Los conceptos densos, tales como «honesto», «cobarde» o «trato degradante» son conceptos que más allá de su carga prescriptiva tienen una marcada dimensión descriptiva que haría posible que se predique la verdad o falsedad y, por tanto, la objetividad, de los juicios morales que los contienen ${ }^{52}$. Sin embargo, de acuerdo con él mismo ${ }^{53}$ :

Podría argüirse que el uso de oraciones que contienen conceptos densos por parte de los intérpretes y, también, de los órganos de aplicación del derecho [...] [es] un uso desprovisto de dimensiones evaluativas. La suerte de este argumento depende de la posibilidad de separar netamente la dimensión descriptiva de la dimensión prescriptiva de los conceptos morales densos. Pero aun si esa posibilidad queda en pie, el intérprete o el aplicador precisan moldear el concepto, ponerlo en relación con otros conceptos e, inevitablemente, para moldear conceptos morales es preciso disponer de un trasfondo moral sobre el cual trabajar. Esto es, es necesaria una red conceptual donde los conceptos morales ocupan algunos de los nodos y esa red conceptual debe controlarse, en una especie de equilibrio reflexivo, con nuestras intuiciones, para ello es preciso embarcarse en una reflexión moral.

Según creo, la argumentación de MORESO no hace sino presuponer una forma de teoría metaética constructivista, similar a la de NINO aquí mencionada. Al hablar del moldeado del concepto, MORESO implica los «ajustes» a los que aludía NiNO, e incluso se refiere explícitamente al equilibrio reflexivo rawlsiano que sirve según el autor argentino como procedimiento para justificar conclusiones morales. La última línea transcripta es evidentemente significativa a este respecto.

En este sentido, el argumento que utiliza MORESO para objetar que sea necesario suscribir alguna forma de objetivismo moral parece más bien abonar la tesis contraria

creo, no es la formulación adecuada del correspondiente cuerno del dilema. Se trata más bien de que deba abandonarse el convencionalismo, y asumirse un objetivismo realista en materia moral. La salida del dilema defendida centralmente en el presente trabajo se basa, justamente, en la posibilidad de asumir cierto tipo de objetivismo moral sin por ello renunciar al convencionalismo (y por ende sin comprometerse con un realismo moral —ontológico- fuerte).

${ }_{50}$ Este trabajo fue escrito con anterioridad a la difusión de nuevos trabajos de José Juan MorESO sobre el tema. En efecto, en esta nueva etapa MORESO parece dar pistas de haber modificado su posición, de una manera que puede decirse se hace eco de críticas en la línea de la que presento en esta sección. Vid. MORESO, 2013.

51 MoreSO, 2002: 93 y ss.

52 Ibid., 99-100.

53 Ibid., 100 (resaltados en el original). 
- porque la presupone- de que en verdad el incorporacionismo requiere de dicho objetivismo para no caer en el ámbito de la crítica de BAYÓN sobre su posible subsunción en el positivismo jurídico excluyente. La «objetividad» de una moral crítica del tipo de la pretendida por teorías constructivistas como la de NiNO (esto es, que no es totalmente ajena a las convenciones sociales sino que se mantiene con ellas en una situación de ajustamiento recíproco) es lo que permite no caer en el convencionalismo fuerte que conduciría al positivismo jurídico excluyente y su también fuerte versión de la tesis de las fuentes sociales. La identificación y aplicación del derecho puede no agotarse en la mera constatación de una serie de hechos sociales, sino que puede eventualmente exigir el desarrollo de un genuino razonamiento moral.

No quiero con esto afirmar que la distinción entre conceptos morales densos y ligeros sea insostenible o inútil, ni que sea imposible trabajar avalorativamente con conceptos morales, sino simplemente que el argumento que MORESO ofrece para desligar al positivismo jurídico incluyente de la necesidad del objetivismo moral es susceptible de, al menos, un cuestionamiento. MORESO intenta mostrar que el positivismo jurídico incluyente no depende de la verdad del objetivismo moral, porque es posible manejar un conjunto de conceptos morales, los densos, que poseen contenidos no sólo evaluativos, sino también descriptivos, de modo que pueden tenerse parámetros de corrección, para los razonamientos que los involucran, en los parámetros que de hecho hay para verificar la corrección de dichos contenidos descriptivos. Así, incluso si el objetivismo moral fuera falso, no quedaría directamente allanado el camino para la discreción judicial, porque el contenido descriptivo de los conceptos morales densos sí está sujeto a criterios de contrastación con los que juzgar la adecuación de los razonamientos que los incluyen.

Esto no sólo tiene el problema de que en definitiva sería sólo aplicable y útil respecto del uso de conceptos morales densos, pero no de los ligeros. Como he intentado mostrar, el tipo de razonamiento con que epistemológicamente resultaría, de la mano de la estrategia de MORESO, que ha de llevarse a cabo la labor adjudicativa mediando conceptos morales densos, sería precisamente el tipo de razonamiento con el que de acuerdo al constructivismo ético reflexionamos moralmente y edificamos y descubrimos verdades morales.

El presente punto contra el argumento de MORESO es en definitiva lo que marcara HART en un discutido pasaje de su Postscript, donde deja abierta la cuestión sobre si su versión inclusiva de positivismo implica que las remisiones a la moral sólo dan espacio creador al juez o si, en cambio, constituyen una prueba (moral) para la determinación del derecho preexistente. La deja abierta — dice allí- porque también deja abierta la cuestión, lógicamente anterior, de si los juicios morales tienen «nivel objetivo» ${ }^{54}$. La objetividad de los juicios morales es determinante de que la remisión que hagan los

${ }^{54}$ HART, 2000: 30-31. Un problema de dicho pasaje es, creo, que a continuación sostiene que la teoría del derecho no debe comprometerse con posiciones controvertidas de filosofía moral. Evidentemente, es exactamente eso mismo lo que HART está haciendo al sostener que el reenvío al razonamiento moral para la identificación del derecho será que se trata, o bien de un modo de descubrimiento de derecho preexistente, o bien de una mera habilitación de la discrecionalidad judicial, según el objetivismo moral sea verdadero o falso, respectivamente. Aunque para HART no hay mayores diferencias prácticas entre ambos casos; me parece evidente que las consecuencias son muy diferentes cuanto menos en términos teóricos (de descripción y explicación de la praxis jurídica) y esa, la teórica, justamente, parece ser la misión central de la teoría general del derecho. 
materiales jurídicos a ciertos contenidos morales sea parte del proceso por el cual los jueces deben descubrir derecho preexistente o, en cambio, sólo una mera habilitación para que éstos ejerzan su discrecionalidad, creando derecho nuevo para resolver casos particulares, de acuerdo a convicciones y posturas personales insusceptibles de ser cuestionadas en función de algún criterio (jurídico) de corrección predeterminado.

A partir de aquí hay, creo, un punto fuerte a favor de la tesis más general de que la autonomía conceptual del positivismo inclusivo está supeditada al objetivismo moral. Esto es, la plausibilidad teórica definitiva del incorporacionismo depende de la verdad del objetivismo moral. Si este último fuese falso, toda apelación a contenidos morales como elemento determinante de la validez jurídica de una norma no sería más que una habilitación a la discreción de los jueces para la creación de derecho nuevo. Por un lado, no habrá posibilidad de que la corrección de una decisión tomada en ese contexto dependa del acaecimiento de ciertos hechos sociales, pero, por el otro, tampoco será el caso de que sea necesario el desarrollo de un tipo específico de razonamiento, el moral, que conlleve una respuesta correcta de la cuestión a decidir; por la simple razón de que si el objetivismo moral es falso, no hay razonamiento moral que pueda llevar a ninguna respuesta correcta, pues no hay corrección moral: no hay algo que descubrir como la respuesta (preexistente) para un caso, sino con suerte una respuesta para dar en el momento que resulta adecuada según determinados intereses.

Ambas opciones -1) corrección siempre dependiente del mero acaecimiento de ciertos hechos sociales y 2) corrección independiente de una inexistente verdad moral - son igualmente satisfactorias para un positivista excluyente, como dos caras de una misma moneda. Sin embargo, el incorporacionista debe asumir cargas teóricas mayores: requiere que la primera opción no sea el caso, a la vez que necesita que haya ciertas respuestas morales correctas o verdaderas para así evitar la conclusión de que toda consideración de un contenido moral implica una decisión, más o menos arbitraria, y no sujeta a un control interno al derecho de cómo ha de resolverse en un cierto caso. Es decir, ninguna de las opciones debe ser adecuada. De lo contrario, el positivismo jurídico incluyente habrá resultado llanamente incorrecto, o al menos fagocitado por la versión excluyente. Pero nótese que el compromiso con la falsedad de la segunda opción no es ni más ni menos que el compromiso con alguna forma de objetivismo moral ${ }^{55}$.

\section{CONCLUSIÓN}

De acuerdo con Juan Carlos BAYÓN, el positivismo jurídico incluyente, al pretender incorporar criterios de corrección moral para evaluar la validez jurídica, cae irremediablemente en el dilema entre:

55 Han sido varios los intentos por mostrar, como MORESO, que la plausibilidad conceptual del positivismo jurídico incluyente no depende de la verdad del objetivismo moral. Vid., por ejemplo, SOPER, 1998, KRAMER, 1999, HiMmA, 1999. Un análisis más elaborado debería estudiar críticamente esos otros intentos y mostrar cómo fallan en abonar la independencia teórica afirmada. En la investigación más amplia de la que, según he mencionado en los agradecimientos, el presente trabajo es parte, he intentado este análisis más exhaustivo, pero su adecuada exposición no puede sino posponerse para otra ocasión, puesto que llevaría un espacio considerable que fracturaría la unidad del presente ensayo. En todo caso, puede verse un pequeño repaso de dichos intentos en ETCHEVERRY, 2006: 343 y ss. 
1. Diluirse en el positivismo excluyente por remitir, en propiedad, a los acuerdos sociales sobre la corrección moral (esto es, a hechos sociales, la llamada «moral social»); o

2. Renunciar al convencionalismo al que estaría primariamente comprometido por abrazar una forma (débil) de la tesis de las fuentes sociales del derecho, al verse en la necesidad de suscribir alguna clase de objetivismo moral que apele a la deliberación moral «genuina» (que según BAYÓN sería aquélla no constreñida por convenciones sociales).

Empero, en función de lo que he intentado mostrar a lo largo de estas páginas, el convencionalismo profundo que delinea el propio BAYÓN en su trabajo — caracterizado por la apelación a un trasfondo de criterios compartidos y no por un acuerdo específico sobre las aplicaciones concretas de las reglas- puede precisamente ser utilizado por el positivismo jurídico incluyente para escapar al dilema al que se lo enfrenta, pues permite hablar de convenciones interpretativas no vacías, que no se autoanulan, y que son las que necesita para sostener conjuntamente sus pretensiones convencionalistas y de diferenciación de las tesis excluyentes. Incluso hay elementos adicionales para reforzar esto, como la idea de convenciones en sentido débil (i. e., «consensos por convicción»), que permite dar cuenta del tipo de carácter convencional que adscriben a la moral las metaéticas constructivistas, por oposición a (o más bien, como un intermedio entre) las meras convergencias irreflexivas, por un lado, y al colapso de la moral crítica en la positiva, por el otro.

Según el autor español, sin embargo, no puede pretenderse que el tipo de actividad que requeriría el convencionalismo profundo para la identificación del derecho por parte de un juez pueda confundirse con el genuino razonamiento moral, porque el razonamiento moral no puede estar constreñido por convenciones y la actividad del juez sí lo está. No obstante, esta afirmación puede ser contradicha al menos en función de la adopción de una teoría metaética objetivista (como la de NiNO, aquí someramente expuesta) que entienda a la moral como una práctica discursiva condicionada por - y a la vez condicionante de- nuestras convenciones sociales, desarrollada a través de un procedimiento específico de argumentación sustantiva colectiva. Esto es, un tipo de metaética que, precisamente, dota de sentido a la imagen de la práctica moral como una convención débil.

Por supuesto, se trata de una conclusión muy modesta. No he dado razones para adoptar una postura en metaética como la que aquí he referido ${ }^{56}$. Se trata de una conclusión condicional y cautelosa. Y es claro que hay gran diversidad de teorías metaéticas disponibles. Quizá hasta podría resultar que la teoría de NiNO y aun todo el constructivismo moral kantiano constituya una reconstrucción conceptual profundamente insatisfactoria en la compleja pluralidad de las sociedades contem-

${ }_{56} \mathrm{Ni}$ en el sentido de reconstrucción conceptual de nuestras prácticas morales discursivas de hecho, ni en el sentido normativo de cómo deberían ser dichas prácticas si queremos mejorarlas de algún modo. Pero claramente, el sentido manejado a lo largo de todo el texto, dado el interés de esta investigación, es el primero. Es decir, la plausibilidad del núcleo de mi análisis está sujeta a la del constructivismo metaético entendido como reconstrucción conceptual del discurso moral tal como éste de hecho es. Aun así, en la sección 4 propuse un esbozo de argumento de acuerdo con el cual el incorporacionismo podría tener una vía de escape al dilema de Bayón incluso de fallar el constructivismo en este aspecto. 
poráneas; pero ello sería ajeno al enfoque aquí adoptado. Por otro lado, lo dicho en estas páginas no pretende excluir el debate sobre muchos otros puntos tocados por el sustancioso trabajo de BAYÓN y sobre los rumbos del positivismo jurídico contemporáneo en general.

No obstante, de la discusión del dilema de Bayón y la solución a éste propuesta puede derivarse la atención al análisis de la relación conceptual entre el positivismo jurídico incluyente y el objetivismo moral. Un esbozo de conclusión — adicional— de este trabajo, es entonces que hay razones para pensar que, en efecto, hay una dependencia conceptual del primero respecto del segundo. De este modo, puede afirmarse que si el objetivismo moral es falso, entonces el incorporacionismo no tiene sustento teórico autónomo, su tesis de que es posible que contingentemente se deba recurrir al razonamiento moral genuino para identificar derecho preestablecido es falsa, y su destino no es otro que la disolución (en el positivismo excluyente) y el olvido.

\section{BIBLIOGRAFÍA}

Alchourrón, C. E., y Bulygin, E., 1975: Introducción a la metodología de las ciencias jurídicas y sociales, Astrea.

- 1991: Análisis lógico y derecho, Centro de Estudios Constitucionales.

ARENA, F. J., 2012: «Desacuerdos ambiguos, convenciones equívocas», en P. LUQUE y G. B. RatTi (eds.), Acordes y desacuerdos. Cómo y por qué los juristas discrepan, Marcial Pons, 279 y ss.

BAYÓN, J. C., 2002: «Derecho, convencionalismo y controversia», en P. NAVARRO y M. REDONDO (comps.), La relevancia del Derecho: ensayos de filosofía jurídica, moral y política, Gedisa.

Brennan, J. M., 1977: The Open-Texture of Moral Concepts, Barnes \& Noble.

Bulygin, E., 2006: El positivismo jurídico, Fontamara.

Celano, B., 2009: Derecho, justicia, razones, A. Greppi y F. LAPORTA (trads.), Centro de Estudios Políticos y Constitucionales.

Coleman, J. L., 1998: «Authority and Reason», en R. P. GeOrge (ed.), The Autonomy of Law. Essays on Legal Positivism, Oxford Clarendon Press.

- 2001: The Practice of Principle. In Defence of a Pragmatist Approach to Legal Theory, Oxford University Press.

DwOrKIN, R., 1978: Taking Rights Seriously, Duckworth.

- 1986: Law's Empire, Fontana Press.

ETCHEVERRY, J. B., 2006: El debate sobre el positivismo jurídico incluyente, UNAM.

García-Carpintero, M., 2010: Las palabras, las ideas y las cosas, Ariel.

Hart, H. L. A., 1963: El concepto de Derecho, G. CARrió (trad.), Abeledo-Perrot.

- 2000: Post scriptum al concepto de derecho, R. TAMAYO (trad.), UNAM (publicado originalmente en 1994, como agregado a la 2. ${ }^{\text {a }}$ ed. — por P. BuLLOCH y J. RAZ— de The Concept of Law).

Himma, K. E., 1999: «Incorporationism and the Objectivity of Moral Norms», Legal Theory, núm. 5.

Kramer, M. H., 1999: «Coming to Grips With the Law: In Defense of Positive Legal Positivism», Legal Theory, núm. 5.

- 2004: Where Law and Morality Meet, Oxford University Press. 
Moreso, J. J., 2002: «En defensa del positivismo jurídico inclusivo», en P. NAVArRo y M. C. REDONDO (comps.), La relevancia del Derecho: ensayos de filosofía jurídica, moral y política, Gedisa.

- 2013: Ethica More Iuridico Incorporata, Fontamara.

NinO, C. S., 1989a: Ética y derechos humanos, 2. ${ }^{\text {e }}$ ed., Astrea.

- 1989b: El constructivismo ético, Centro de estudios constitucionales.

- 1992: Fundamentos de derecho constitucional. Análisis filosófico, jurídico y politológico de la práctica constitucional, Astrea.

- 1994: Derecho, moral y política, Ariel.

ORunesu, C., 2007: «Sobre la inconsistencia teórica del positivismo jurídico incluyente», Análisis filosófico, XXVII, núm. 1.

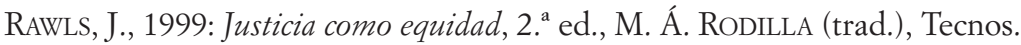

RAz, J., 1985: La autoridad del Derecho. Ensayos sobre Derecho y Moral, R. TAMAYo (trad.), UNAM.

Ródenas, Á., 2003: «¿Qué queda del positivismo jurídico?», Doxa. Cuadernos de Filosofía del Derecho, núm. 26.

Soper, E. P., 1998: «Two Puzzles from the Postscript», Legal Theory, núm. 4.

Vilajosana, J. M., 2010: «Una defensa del convencionalismo jurídico», Doxa. Cuadernos de Filosofía del Derecho, núm. 33. 